\title{
On the genus Epidiplosis Felt (Diptera: Cecidomyiidae) in East Asia, with descriptions of four new species
}

\author{
Jun Li \& Wenjun Bu
}

Li, J. \& Bu, W. 2006: On the genus Epidiplosis Felt (Diptera: Cecidomyiidae) in East Asia, with descriptions of four new species. — Entomol. Fennica 17: 79-86.

Eight species of the genus Epidiplosis Felt are reported, seven from China and one from Russian Far East. Two species from China, E. indica Grover \& Chandra and E. reflexa Mamaev, and one from the Russian Far East, E. filifera (Nijveldt), are newly recorded. Four species are described as new to science: E. bicornuta sp. nov., E. campanulata sp. nov., E. lari sp. nov. and E. tuberoforcipata sp. nov. The genus is redescribed. A key to the species is given and all the species are illustrated.

Jun Li, Department of Biology, College of Life Sciences, Nankai University, Weijin Road, Tianjin, 300071, China; e-mail: lijunnku@126.com. Present address: Department of Biology, Zhaoqing University, Zhaoqing, 526061, China Wenjun Bu (corresponding author), Department of Biology, College of Life Sciences, Nankai University, Weijin Road, Tianjin, 300071, China; e-mail: wenjunbu@nankai.edu.cn

Received 12 January 2004, accepted 24 November 2004

\section{Introduction}

The genus Epidiplosis was described by Felt in 1908. The type species is Epidiplosis sayi from Nassau, New York, USA. Nijveldt (1965) described a new genus, Gersonomyia for G. filifera Nijveldt. Mamaev (1969) synonymized the genus Gersonomyia with Epidiplosis and described Epidiplosis reflexa Mamaev from Moscow, Russia. Grover \& Chandra (1988) described Epidiplosis indica Grover \& Chandra from India. Mo (2000) and Mo and Liu (2000) described Epidiplosis simulifilifera Mo and Epidiplosis triangularis Mo \& Liu, respectively, from China. Until now, six species have been reported, from USA, Israel, Russia, India and China. Except for Epidiplosis filifera (Nijveldt), which prey on Ceroplastes floridensis Comstock (= Paracerostegia floridensis (Comstock)) (Coccidae) and
Lepidosaphes beckii (Newman) (= Mytilaspis beckii (Newman)) (Diaspididae) on citrus in Israel (Nijveldt 1965), the biology of other species of the genus are unknown.

The fauna of Chinese gall midges has not been sufficiently studied. Only about a hundred species of the family have been reported. While studying gall midges of the supertribe Cecidomyiidi, eight species of Epidiplosis from China and Russian Far East were discovered, of which four are described as new to science.

\section{Materials and methods}

The specimens involved in the present paper were collected in the East Asia from 1993 to 2002 with Malaise trap, sweep net and light trap by one of the authors, Dr. Wenjun $\mathrm{Bu}$, and other colleagues 
of Nankai University. Specimens were dipped and preserved in the vials with $70 \%$ alcohol in the field as soon as collected. Each individual was dissected into four parts and mounted in Canada balsam on a microscope slide. The morphological terminology follows Gagné (1981).

Type specimens and other new material are deposited in the Institute of Entomology, College of Life Sciences, Nankai University, Tianjin, China.

\section{Genus Epidiplosis Felt, 1908}

\subsection{Redescription of the generic characters}

Male. Eyes confluent above. Palpus 4-segmented. Antenna with 12 binodal flagellomeres, each with 3 whorls of regular circumfilar loops and 2 whorls of setae; first and second flagellomeres fused. Wing hyaline, vein $\mathrm{R}_{5}$ reaching the costa beyond or at the wing apex, vein Rs weak basally or invisible, vein $\mathrm{Cu}$ forked, vein $\mathrm{PCu}$ parallel with $\mathrm{Cu}$. Tarsal claws simple. Empodium as long as or slightly shorter than claws. Terga and sterna of abdomen membranous, at least terga 2-6 with single mesally interrupted row of caudal setae and sterna 2-6 with double row of caudal setae. Genitalia: cerci discrete, broadly convex apically; hypoproct simple, convex or slightly emarginate apically; gonocoxite plump, with a slender, glabrous, apicodorsal projection with or without a long subapical seta; gonostylus slightly sinuate, slender from the middle, usually bearing two setae on distal half, toothed apically; aedeagus of various shape: usually narrowed at base, broadened and variously modified at apex, with 4 hyaline sensory pores midventrally. There is a membranous structure between hypoproct and aedeagus.

Female. Unknown.

\subsection{Discussion}

The characters of the genus given by Felt (1908, 1921) were relatively simple, so the generic characters used in most of the articles dealing with this genus were mainly those given by Nijveldt (1965) for the genus Gersonomyia. Gagné (1973) synopsized the generic characters of the genus based on the type species. Grover and Chandra (1988) expressed their opinion that the description of genitalia in the generic characters of Gersonomyia was not proper and provided revised generic characters. In this study, some problems of generic characters were revealed, thus a further revision of the generic characters of Epidiplosis is still necessary.

The number of antennal segments of Gersonomyia filifera was described and illustrated as " $2+10$ " by Nijveldt (1965). Harris (1967) re-examined Nijveldt's types, but the number could not be determined and was expressed as " $2+10$ ?". Grover and Chandra (1988) gave a range of " $2+10-12 "$ as the generic characters. All eight species involved in this paper have " $2+12$ " antennal formula. The terminal flagellomere in Nijveldt's (1965) figure looks like the basal node of broken flagellomere 10. So, as far as we know, there are no " $2+10$ " formula antennae in the supertribe Cecidomyiidi.

In the description of generic characters of Grover and Chandra (1988), "terminal clasp segment ..., triangular apically having a thread-like extremity;" may not be correct. In Nijveldt's (1965) generic characters, the above description referred to the apical projection of gonocoxite although he miscalled it "harpes". In fact, apices of gonostyli of all known species are not triangular in shape and without a thread-like extremity distally.

The apical projection of gonocoxite may be either curved or straight with a stout seta subapically or at midlength. Most importantly, the apical projection of gonocoxite is situated on the dorsal side, instead of the ventral side as in other genera of Cecidomyiidi. By the way, the aedeagus is not always emarginate apically and longer than hypoproct.

Some important characters of the abdomen were not mentioned formerly. The terga and sterna are membranous; terga 2-7 have one row of caudal setae, but interrupted in the middle, and sterna 2-6 have only a double row of caudal setae. The caudal setae on tergum 8 can not be seen and setae on sterna 7-8 and tergum 7 are not always so regular as on others (Fig. 1). 


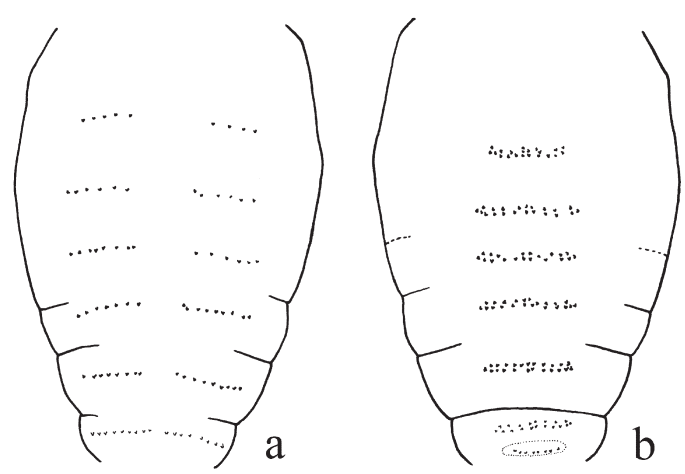

Fig. 1. Abdomen of E. campanulata sp. nov. (male). - a. Dorsal view. - b. Ventral view.

\subsection{Classification}

In this paper, we separate all species of the genus into two groups according to the presence or absence of the delta-shaped projection at distal half of the gonostylus. One is the E. sayi group without the delta-shaped projection, including Epidiplosis bicornuta sp. nov., E. campanulata sp. nov., E. filifera, E. lari sp. nov., E. reflexa, E. sayi and $E$. simulifilifera. The other group, the $E$. indica group, has the delta-shaped projection and includes E. indica, E. triangularis and E. tuberoforcipata sp. nov.

\section{Key to species of Epidiplosis of the world (males)}

1. Gonostylus with a delta-shaped projection outside in distal half 2 (E. indica group)

- Gonostylus without delta-shaped projection 4 (E. sayi group)

2. Gonostylus with a big basal tubercle, which is bearing a long seta distally

E. tuberoforcipata sp. nov.

- Gonostylus without basal tubercle

3. Aedeagus with 2 extremely long, sclerotized, furcate horns; gonostylus with delta-shaped projection about two times as long as its basal width E.triangularis Mo \& Liu

- Aedeagus with 3 small, triradiate, sclerotized projections; gonostylus with delta-shaped projection about as long as its basal width

E. indica Grover \& Chandra
4. Aedeagus horn-shaped, distal margin variously modified

- Aedeagus not horn-shaped, acutely angled apicolaterally

5. Aedeagus with a pair of slender long sclerotized projections apicodorsally, with a pair of wing-like sclerotized structure ventrally

E. lari sp. nov.

- Aedeagus with a pair of stout sclerotized cornute projections apicodorsally, without wing-like sclerotized structure

E. bicornuta sp. nov.

6. Apicodorsal projection of gonocoxite with a seta at middle; aedeagus with a subapical bellshaped sclerotized projection at dorsal center

E. campanulata sp. nov.

- Apicodorsal projection of gonocoxite with a seta at or near apex; aedeagus without bellshaped sclerotized projection

7. Apicolateral angles of aedeagus long, each more than $1 / 3$ apical width of aedeagus 8

- Apicolateral angles of aedeagus short, each less than $1 / 4$ apical width of aedeagus 9

8. Body length $0.6 \mathrm{~mm}$; apicodorsal projection of gonocoxite shorter than gonostylus

E. sayi Felt

- Body length 1.2-1.5 mm; apicodorsal projection of gonocoxite longer than gonostylus

9. Genitalia with shoveled aedeagus

E. reflexa Mamaev

- Genitalia without shoveled aedeagus

E. simulifilifera Mo

E. filifera (Nijveldt)

Remarks. E. reflexa Mamaev is similar to E. sayi Felt; E. simulifilifera Mo is similar to E. filifera (Nijveldt). The diagnostic characters used to distinguish the two pairs of species in couplet 8 and 9 of the key is based on the original descriptions and figures.

\section{Species of Epidiplosis in East Asia}

\subsection{Epidiplosis bicornuta sp. nov. (Fig.2)}

Type material. Holotype ${ }^{\Uparrow}$ : China, Shaanxi Province, Ningshan, Huoditang $\left(33.26^{\circ} \mathrm{N}, 108.26^{\circ} \mathrm{E}\right)$, net sweeping, 15.VIII.1994, W.-J. Bu leg. Para- 


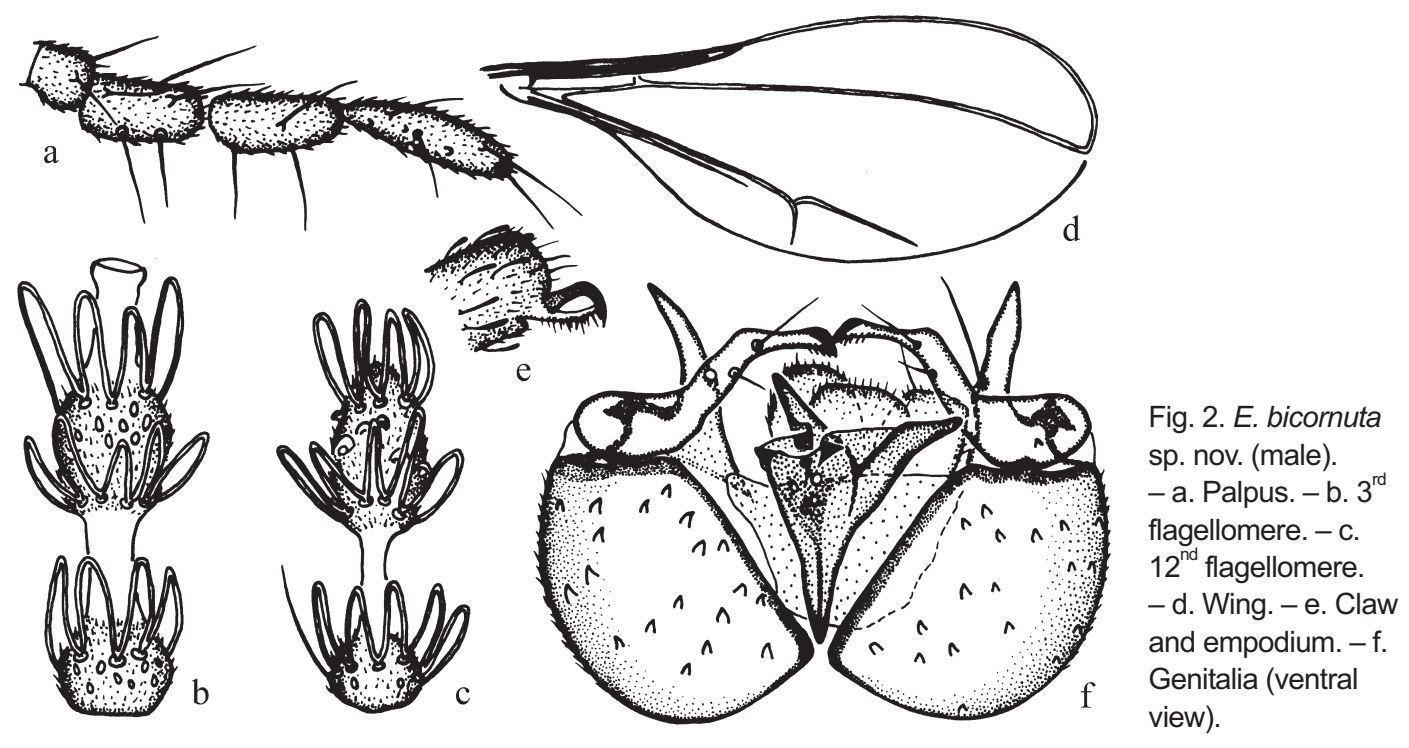

types: same data as holotype but 14.-15.VIII. 1994, 4 ふึે.

Diagnosis. This new species is most similar to E. filifera (Nijveldt), but differs from the latter in having a pair of large hornshaped lateral aedeagal projections dorsally, and a pair of small triangular projections apicoventrally.

Description. Male: Wing length 1.1 to 1.3 $\mathrm{mm}$. Eye bridge 9 facets long at vertex. Genitalia: gonostylus with 2 short setae near middle; aedeagus horn-shaped, sclerotized, with a pair of large, strongly sclerotized horn-shaped projections apicodorsally, and a pair of strongly sclerotized, small triangular projections apicoventrally.

Etymology. The name bicornuta is an adjective meaning "two-horned", referring to the two large apicodorsal projections of aedeagus.

\subsection{Epidiplosis campanulata sp. nov. (Fig.3)}

Type material. Holotype $\delta^{\top}$ : China, Shaanxi Province, Ningshan, Xunyangba $\left(33.33^{\circ} \mathrm{N}, 108.33^{\circ}\right.$ E), net sweeping, 1.VIII.1994, W.-J. Bu leg. Paratype: same data as holotype, $1 \hat{\delta}$.

Diagnosis. This new species is similar to $E$. filifera (Nijveldt) and E. reflexa Mamaev, but it differs from the two species in apicodorsal projection of gonocoxite with a seta at middle, aedeagus with a sclerotized, bell-shaped projection arised from subapex.
Description. Male: Wing length about 1.1 $\mathrm{mm}$. Eye bridge 8 to 9 facets long at vertex. Genitalia: the projection of gonocoxite inflexed, tapered gradually and pointed apically, cornute, with a seta submedially; gonostylus with two big sockets bearing short setae near middle; aedeagus sclerotized, cornute at basal $3 / 4$, with a pair of sharp, strongly sclerotized horns protruding in opposite directions at distal fourth, tabulate or slightly rounded terminally, subapicodorsally with a middle sclerotized bell-shaped projection.

Etymology. The specific name campanulata is an adjective meaning "bell-shaped", referring to the shape of caudal projections of the aedeagus.

\subsection{Epidiplosis filifera (Nijveldt, 1965)} (Fig. 4)

Gersonomyia filifera Nijveldt, 1965: 41 (original description).

Epidiplosis filifera (Nijveldt): Mamaev, 1969: 415. (new combination).

This species is recorded for the first time from Russian Far East.

Specimen examined. Russia, Prymorye, Khasansk Region, Kedrovaja Pad, Kaskadny Stream $\left(43.09^{\circ} \mathrm{N}, 131.53^{\circ} \mathrm{E}\right)$, net sweeping,

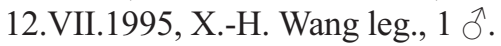

Distribution. Israel; Russia (Far East). 
Fig. 3. E. campanulata sp. nov. (male). - a. Palpus. - b. $3^{\text {rd }}$ flagellomere. - c. $12^{\text {nd }}$ flagellomere. - d. Wing. - e. Claw and empodium. - f. Genitalia (ventral view). - g. Genitalia (dorsal view). - h. Eedeagus (paratype).
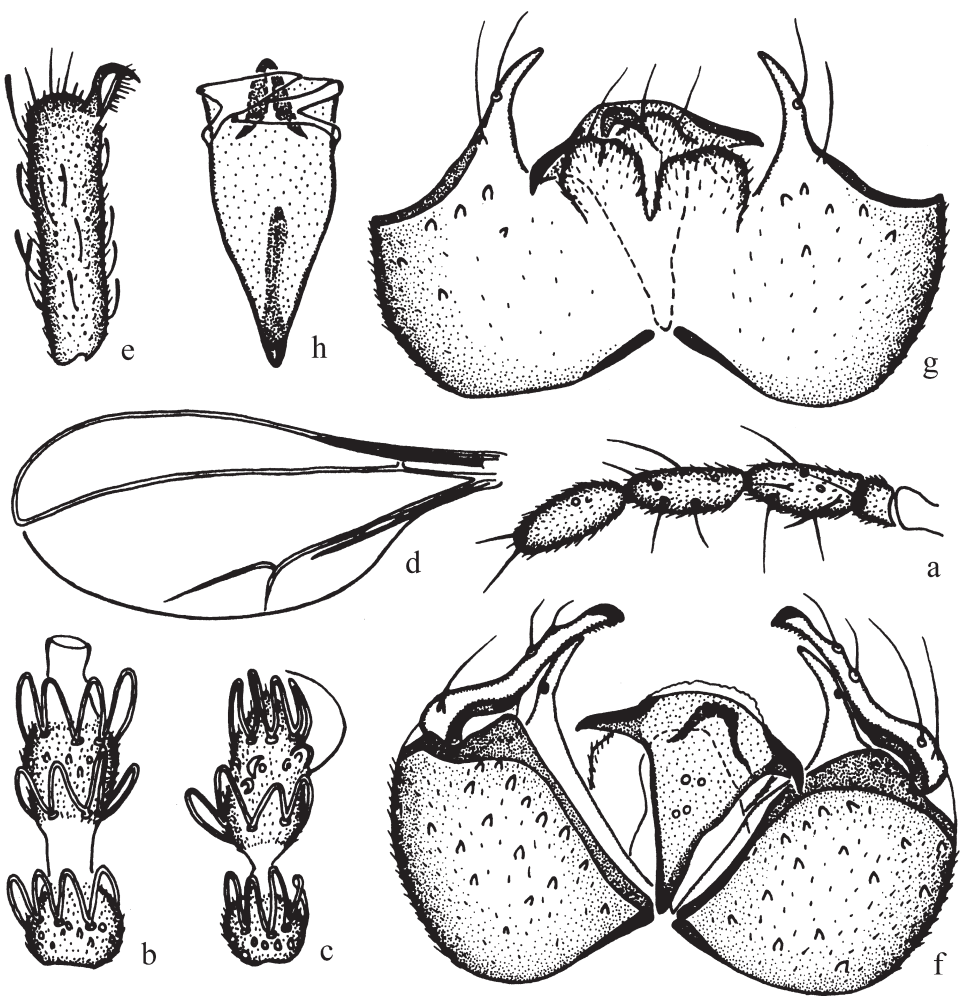

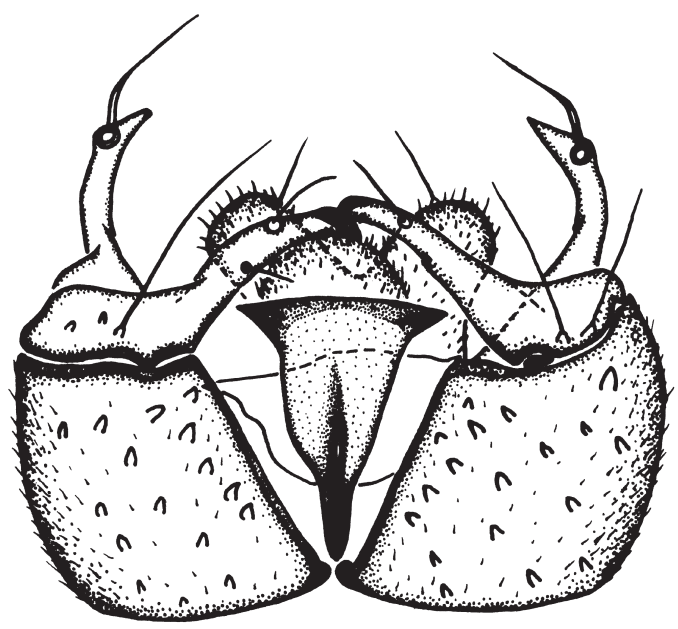

Fig. 4. Genitalia of E. filifera (Nijveldt) (ventral view).

\subsection{Epidiplosis indica Grover \& Chandra, 1988 (Fig. 5)}

Epidiplosis indica, Grover \& Chandra, 1988: 158.

This species is recorded for the first time from China.

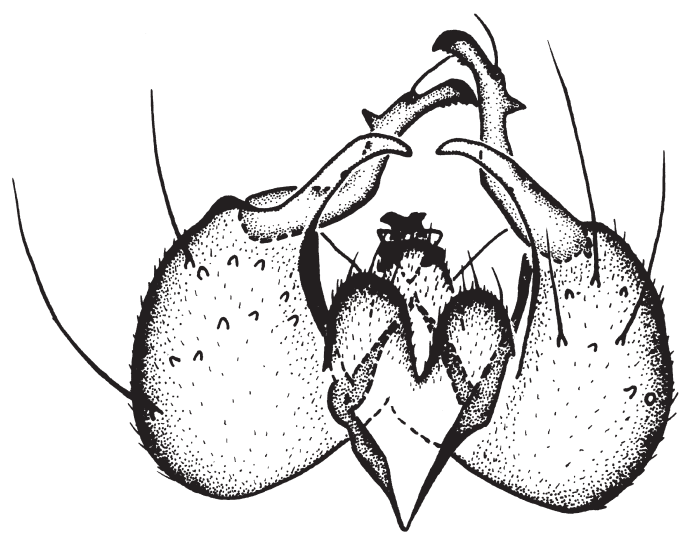

Fig. 5. Genitalia of E. indica Grover \& Chandra (dorsal view).

Specimen examined. China, Guangxi Zhuangzu Autonomous region, Shangsi, Hongqi Forestry Center $\left(22.09^{\circ} \mathrm{N}, 107.58^{\circ} \mathrm{E}\right), 260 \mathrm{~m}$, Malaise trap, 1.-3.IV.2002, H.-J. Xue leg., $2 \precsim \widehat{\jmath}$; China, Yunnan, Simao, Caiyanghe, Luoluoxinzhaishan, $\left(22.48^{\circ} \mathrm{N}, 100.58^{\circ} \mathrm{E}\right), 1500 \mathrm{~m}$ a.s.l., at light, 22.X.2000, W.-J. Bu leg., 1 ${ }^{\Uparrow}$.

Distribution. China (Guangxi; Yunnan); India. 

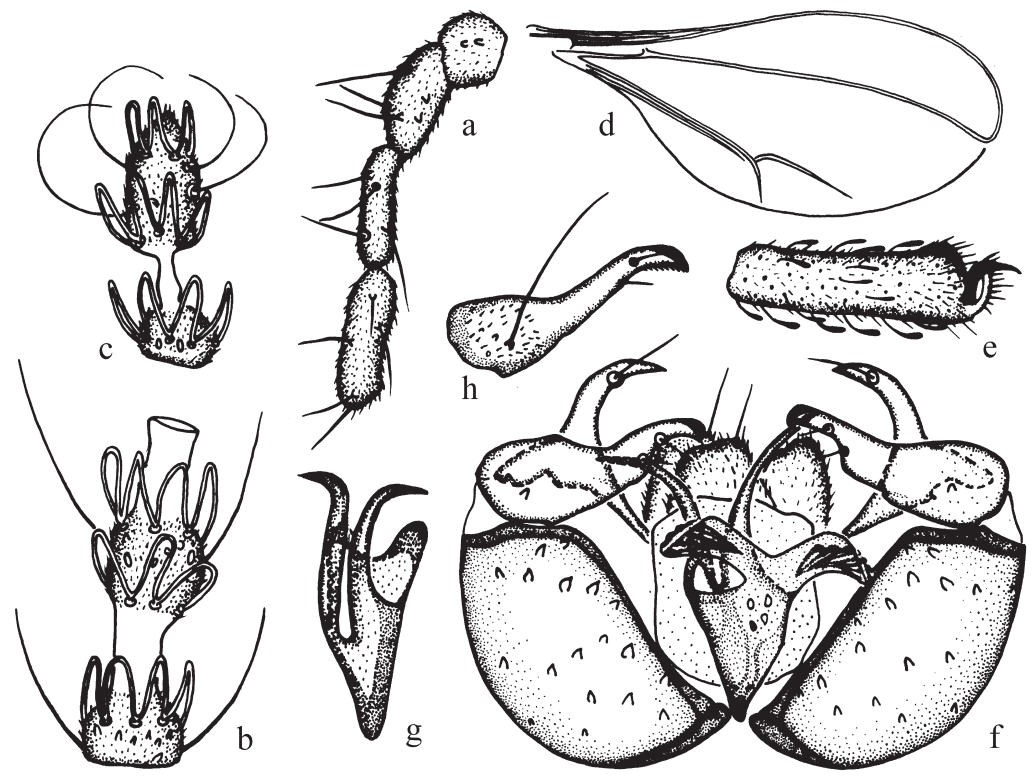

Fig. 6. E. lari sp. nov. (male). - a. Palpus. - b. $3^{\text {rd }}$ flagellomere. - c. $12^{\text {nd }}$ flagellomere. $-d$. Wing. - e. Claw and empodium. $-f$. Genitalia (ventral view). - g. Aedeagus (paratype). - h. Gonostylus (paratype).

\subsection{Epidiplosis lari sp. nov. (Fig. 6)}

Type material. Holotype $\delta^{\Uparrow}$ : China, Guizhou Province, Libo $\left(25.24^{\circ} \mathrm{N}, 107.52^{\circ} \mathrm{E}\right)$, at light, 7.VIII.1995, W.-J. Bu leg. Paratype: same data as holotype, 1 ก.

Diagnosis. In the sayi group, the new species allied to E. filifera (Nijveldt) and E. bicornuta sp. nov. Both of E. bicornuta and E. lari have a bellmouthed aedeagus, which are different from E. filifera. The differences of the two new species are: aedeagus of $E$. lari with a pair of wing-like sclerotized structure apicoventrally, and apicodorsal projections of aedeagus are slender and acute.

Description. Male. Wing length about 0.9 to $1.0 \mathrm{~mm}$. Eye bridge 8 facets long at vertex. Genitalia: apicodorsal projection of gonocoxite widened basally, abruptly tapered at middle, inflexed and pointed apically, cornute, with a seta in a round socket subapically; gonostylus with 2 short setae at distal third; aedeagus sclerotized, cornute basally and bell-mouthed distally, with a pair of long slender sclerotized projections apicodorsally, and a wing-like sclerotized structure apicoventrally.

Etymology. The name is the Latin genitive for "sea-gull", referring to the shape of the aedeagal apicoventral projections that resemble a flying sea-gull.

\subsection{Epidiplosis reflexa Mamaev, 1969 (Fig. 7)}

Epidiplosis reflexa Mamaev, 1969: 16.

This species is recorded for the first time from China.

Specimen examined. China, Heilongjiang Province, Ning-an, Jingpo Lake $\left(43.52^{\circ} \mathrm{N}\right.$,

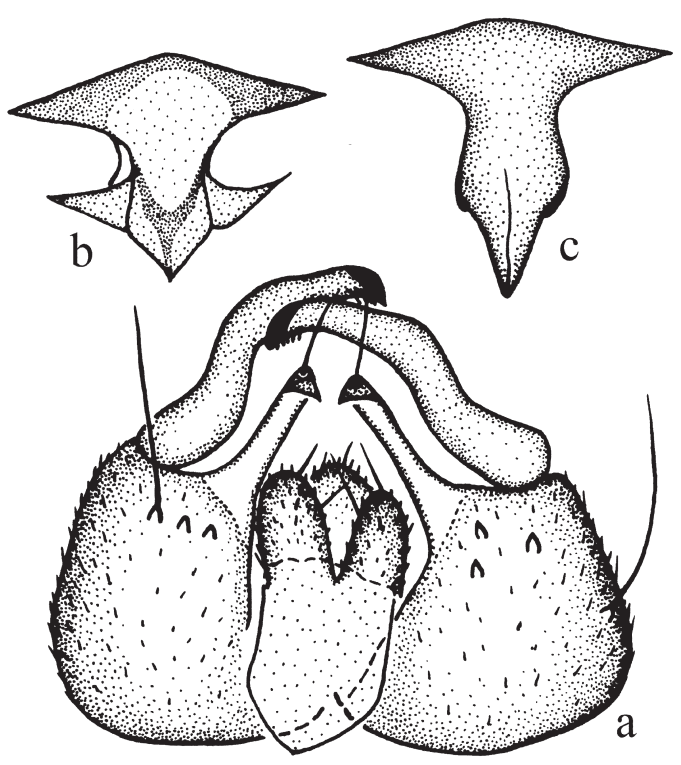

Fig. 7. E. reflexa Mamaev (male). - a. Genitalia (dorsal view). $-b$. Aedeagus (dorsal view). - c. Aedeagus (ventral view). 


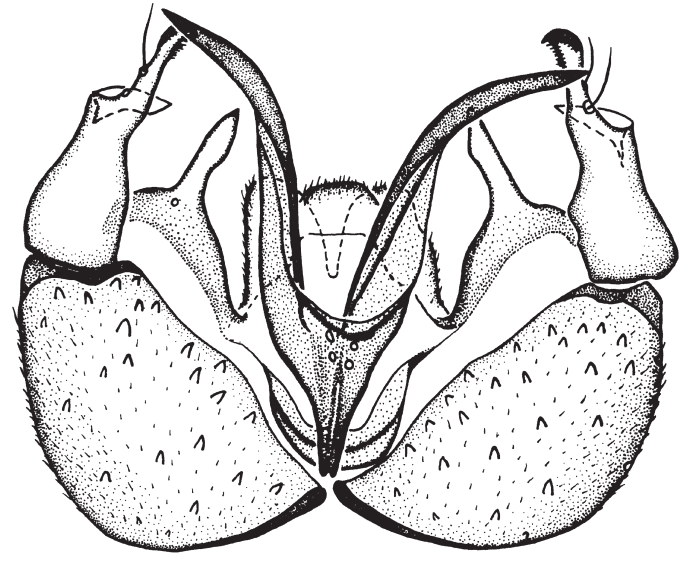

Fig. 8. Genitalia of E. triangularis Mo \& Liu (ventral view).

$128.54^{\circ}$ E, net sweeping, 21.VI.2000, Yu.-X. Jiang leg., 1 ऽ.

Distribution. China (Heilongjiang); Russia (Moscow).

\subsection{Epidiplosis triangularis Mo \& Liu, 2000} (Fig. 8)

Epidiplosis triangularis Mo \& Liu, 2000: 122. Specimen examined. China, Shaanxi Province, Ningshan, Huoditang $\left(33.26^{\circ} \mathrm{N}, 108.26^{\circ} \mathrm{E}\right)$, net sweeping, 15.VIII.1994, W.-J. Bu leg., 1 ${ }^{\lambda}$.

Distribution. China (Hubei; Shaanxi).

\subsection{Epidiplosis tuberoforcipata sp. nov. (Fig. 9)}

Type material. Holotype $\widehat{o}^{\lambda}$ : China, Fujian Province, Wuyishan, Tongmu, Qiliqiao $\left(27.7^{\circ} \mathrm{N}\right.$, $\left.117.6^{\circ} \mathrm{E}\right)$, net sweeping, 25.IV.1993, W.-J. Bu leg. Paratypes: China, Yunnan Province, Kunming, Huahongdong $\left(25.04^{\circ} \mathrm{N}, 102.42^{\circ} \mathrm{E}\right)$, Malaise trap, 6.-8.V.2000, W.-J. Bu leg., 1 §ं; China, Guangxi Zhuangzu Autonomous region, Shangsi, Nanping $\left(22.09^{\circ} \mathrm{N}, 107.58^{\circ} \mathrm{E}\right), 770 \mathrm{~m}$, Malaise trap, 3.-5.IV.2002, H.-J. Xue leg., $1 \hat{\jmath}$.

Diagnosis. In the $E$. indica group, this new species allied to $E$. indica Grover \& Chandra, but it differs from the latter in having horn-shaped aedeagus, with a apicodorsal and a apicoventral cornute projections (without triangular distributed sclerotized projections dorsally and a pair of fork-shaped projections ventrally); gonostylus with a big tumor-like projection basally.

Description. Male. Wing length $1.0 \mathrm{~mm}$. Eye bridge 7 to 8 facets long at vertex. Genitalia: gonostylus slightly broad basally, with a big tumor-like projection, bearing a long seta distally, with a delta-shaped projection at outer side of its
Fig. 9. E. tuberoforcipata sp. nov. (male). - a. Palpus. - b. $3^{\text {rd }}$ flagellomere. - c. $12^{\text {nd }}$ flagellomere. $-\mathrm{d}$. Wing. - e. Claw and empodium. $-\mathrm{f}$. Genitalia (ventral view).
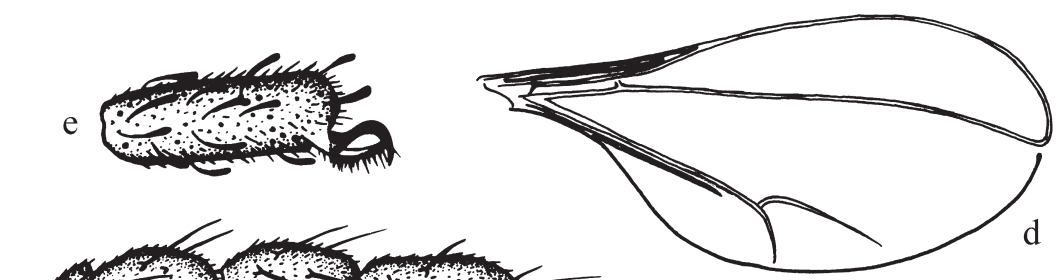

a
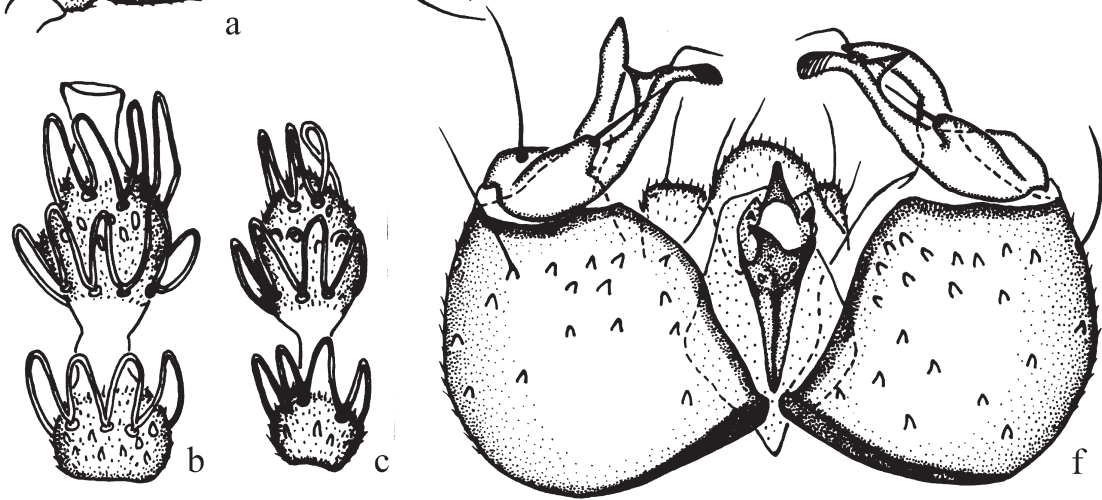
distal half and with 1 short seta at distal third; aedeagus sclerotized, gradually pointed basally, campanulate distally, with a apicodorsal and a apicoventral cornute projections, a pair of small sclerotized triangular projections at both side of the dorsal horn.

Etymology. The name tuberoforcipata is an adjective formed from "tuber-" for swelling and "forceps" with reference to the swelling at base of the gonostylus.

Acknowledgements. We are very grateful to Dr. Gagné, R. J., Systematic Entomology Laboratory, USDA, Washington, D. C., USA, for checking the holotype of Epidiplosis sayi Felt and providing sketch of its genitalia, and for reviewing and amending the manuscript. The authors also wish to express their thanks to Prof. Zheng Le-Yi of Department of Biology, Nankai University, Tianjin, China for his reviewing of the manuscript and to Prof. Wang XinHua, Dr. Xue Huai-Jun and Ms. Jiang Yu-xia of the Department of Biology, Nankai University, Tianjin, China for their assistance in collecting specimens. The Project was supported by "Education Grant" of National Natural Sciences Foundation of China.

\section{References}

Felt, E. P. 1908: Appendix D. New species of Cecidomyiidae II. - N. Y. State Mus. Bull. 124: 286-422.

Felt, E. P. 1921: A study of gall midges, VII. - N. Y. State Mus. Bull. 231-232: 81-240.

Gagné, R. J. 1973: A generic synopsis of the Nearctic Cecidomyiidi (Diptera: Cecidomyiidae). - Ann. Entomol. Soc. Am. 66: 857-889.

Grover, P. \& Chandra, R. 1988: First record of genus Epidiplosis Felt. — Cecid. Int. 9 (3): 125-184.

Harris, K. M. 1967: A systematic revision and biological review of the cecidomyiid predators (Diptera: Cecidomyiidae) on world Coccoidea (Hemiptera: Homoptera). — Trans. R. Entomol. Soc. Lond. 119: 401494.

Mamaev, B. M. 1969: [Family Cecidomyiidae (Itonididae).] — In: Bei-bienko, G.. Ya., (ed.), Keys to the insects of the European part of the USSR. Vol. V. Diptera and Siphonaptera. Part I: 356-420. Leningrad. Published in English, 1988, Amerind Publishing Co., Ltd., New Delhi.

Mo, T. 2000: A new record genus and new species of Cecidomyiidae (Diptera) from China. - In: Zhang Y.L. (ed.), Systematic and faunistic research on Chinese insects. Proceedings of $5^{\text {th }}$ National Congress of insect taxonomy: 184-187. China Agriculture Press, Beijing.

Mo, T. \& Liu, T. 2000: A new species of the genus Epidiplosis (Diptera: Cecidomyiidae) from China. Entomotaxonomia. 22 (2): 122-124.

Nijveldt, W. 1965: A new coccid-eating gall midge from Israel. — Entomol. Ber. Deel. 25: 41-43. 